\title{
Access by the unaccompanied under-16-year-old adolescent to general practice without parental consent
}

\author{
Lin Davies, MB ChB, MrcGP, General Practitioner Principal, The Medical Centre, Helston, UK
}

Correspondence: Dr L Davies, The Medical Centre, Trelawney Road, Helston, Cornwall TR13 8AU, UK. E-mail:

Linda.Davies@HMC.cornwall.nhs.uk

(Accepted 28 April 2003)

Journal of Family Planning and Reproductive Health Care 2003; 29(4): 205-207

\begin{abstract}
Background. The views of primary health care providers concerning their willingness to consult with under-16year-old adolescent patients without the presence of a parent or guardian are not well documented. Many young people believe they have to be aged over 16 years to see their general practitioner (GP) alone. Confidentiality is a major concern for young people. It is important that more is known about the willingness of GPs and practice nurses (PNs) to offer unaccompanied consultations without known parental consent.

Aim. To provide information on the willingness of GPs and PNs to consult with under-16-year-olds and whether policies exist in general practices to facilitate access by unaccompanied under-16-year-olds.
\end{abstract}

Study design. Cross-sectional study using a postal questionnaire.

Setting. Seventeen general practices in the West of Cornwall.

Method. All GPs, PNs and receptionists were sent questionnaires.

Results. The overall response rate was 79\% (166/209 questionnaires). The majority of GPs and PNs (91\%) were willing to consult with unaccompanied under-16-year-olds. A substantial number of primary health care team members are not aware of the existence of any practice policy on access. Only $41 \%$ of receptionists, $46 \%$ of PNs and $38 \%$ of $G P s$ were aware of a definite practice policy.

Conclusions. GPS and PNs are willing to consult with under-16-year-olds without a parent or guardian being present. Many practices in this region do not appear to have policies in place to guide health professionals on under-16 access issues.

\section{Key message points}

- Confidentiality is important to young people when accessing health services.

- Many teenagers believe that they have to be aged over 16 years to see their general practitioner (GP) without a parent being present.

- GPs and practice nurses do see under-16-year-olds without a parent being present and are aware of the rights of young people.

- Health professionals and practices need to have policies in place to guide receptionists on under-16 access issues.

\section{Introduction}

Many adolescents believe they have to be aged over 16 years to see their general practitioner (GP) alone. ${ }^{1}$ This creates a possible barrier to access for a group of patients in which confidentiality has consistently been shown to be a major issue. ${ }^{2-7}$ The views of personnel working in general practice on consulting under-16-year-olds on their own are not considered to be well documented. ${ }^{8}$ It is possible that although it is the right of young people to seek to be seen alone (1989 Children's Act) it may not be accepted practice to allow under-16-year-olds to be seen without first requesting a parent or guardian to be present. 9,10 This view could then be seen by young people as being prescriptive.

One of the two main goals set by the Social Exclusion Unit was to reduce the teenage conception rate by half in under-18-year-olds by $2010 .{ }^{11}$ To achieve this objective there needs to be a service available which young people feel able to access with ease. ${ }^{12}$ Most teenagers have been shown to have attended general practice in the year before pregnancy. ${ }^{13}$ However, teenagers include patients up to 19 years of age and it is not known if under-16-year-olds feel confident about consulting their GP or practice nurse (PN) for contraceptive advice. Access to services by under-16year-olds unaccompanied by adults is important in areas other than contraception, such as sexually transmitted infection, discussions about sexuality, sexual abuse, etc.

An exploratory study was set up to provide information about the views of GPs and PNs regarding their willingness to consult with under-16-year-olds without demanding a parent or guardian to be present and on their understanding of the Fraser Guidelines (issued after the House of Lords' judgement in 1985 on the Gillick case and also known as 'Gillick' competence) (see Box 1). ${ }^{14}$ The author also wished to discover whether there were policies in place within general practice for dealing with access by unaccompanied under-16-year-old patients.

\section{Method}

A questionnaire about health professionals' attitudes and policies on unaccompanied under-16-year-old visits to general practice was devised and piloted at two general practice surgeries in the southwest of England. Comments and suggestions were then incorporated and a revised version was produced. The main study commenced at the beginning of February 2002.

The questionnaire was sent to 17 practices in the West of Cornwall Primary Care Trust (PCT). These practices were chosen because this project initially sought to provide information about local options for young people and, inter alia, was partly funded by a local Health Action Zone (HAZ) fellowship.

\footnotetext{
Box 1: Summary of Fraser Guidelines

A young person is competent to consent to treatment if:

- The young person understands the doctor's advice.

- The doctor cannot persuade the young person to inform his or her parents or allow the doctor to inform parents that he or she is seeking contraceptive advice.

- The young person is very likely to begin or continue having intercourse with or without contraceptive treatment.

- Unless he or she receives contraceptive treatment, the young person's physical or mental health or both are likely to suffer.

- The young person's best interests require the doctor to give contraceptive advice, treatment or both without parental consent.
} 
Before sending out the questionnaires all the practice managers in the West of Cornwall PCT were contacted to explain the aims of the project and to request their cooperation in distributing and collecting the questionnaires. The questionnaire was sent to all doctors, nurses and receptionists, including GP assistants and registrars.

The protocol was granted ethical approval by the Cornwall Research Ethics Committee in March 2001.

\section{Results}

Response rates

Of a total of 25 practices that were approached, 17 agreed to take part in the study and 209 questionnaires were distributed. The overall return rate was $79 \%(166 / 209$ questionnaires).

Breakdown by health professional revealed that $73 \%$ of GPs (53/73), 72\% of PNs (28/39) and $88 \%$ of receptionists (85/97) replied.

\section{Willingness to consult}

Both PNs and GPs were specifically asked whether they would normally agree to consult an unaccompanied under16-year-old. A total of 48/51 (94\%) GPs and 22/26 (85\%) PNs answered that they would normally agree (two GPs and two PNs did not answer this question). These results indicated that in all of the practices surveyed the vast majority of health professionals $(91 \%)$ are willing to consult with unaccompanied under-16-year-old patients. These results were spread across individual practices although they have been presented collectively here.

\section{Practice policies}

GPs and PNs were asked if they had a policy for seeing unaccompanied under-16-year-olds. A total of 17/45 (38\%) doctors who answered this question had a policy, as did $12 / 26$ PNs $(46 \%)$.

The receptionists were asked if they were aware of a practice policy and 33/81 receptionists (41\%) who answered said they knew of such a policy.

Therefore the majority of respondents felt either unable to answer this question or were unaware of a specific policy. It is evident that the majority of reception staff appears to have no clear guidelines for allowing unquestioned access to unaccompanied under-16-yearolds.

The figures differ for GPs, PNs and receptionists. One possible explanation is that more receptionists and PNs are aware of policies than GPs, i.e. a practice may have a policy and some staff members are aware of its existence and some are not.

Influence of actual age on the decision-making process The survey undertook to assess the impact of the adolescent's actual age on the decision to consult with

Table 1 Number (\%) of Yes/No responses from general practitioners, practice nurses and receptionists to offering unaccompanied appointments according to the age of the patient ${ }^{a}$

\begin{tabular}{lrrrrr}
\hline $\begin{array}{l}\text { Respondent/ } \\
\text { response }\end{array}$ & \multicolumn{5}{l}{ Age of patient (years) } \\
\cline { 2 - 6 } & 12 & \multicolumn{1}{c}{13} & \multicolumn{1}{c}{14} & \multicolumn{1}{c}{15} & \multicolumn{1}{c}{16} \\
\hline GP/Yes & $12(31)$ & $15(39)$ & $27(71)$ & $36(95)$ & $46(100)$ \\
GP/No & $27(69)$ & $23(61)$ & $9(29)$ & $2(5)$ & $0(0)$ \\
PN/Yes & $8(36)$ & $5(26)$ & $10(53)$ & $12(63)$ & $21(100)$ \\
PN/No & $14(64)$ & $14(74)$ & $9(47)$ & $7(37)$ & $0(0)$ \\
R/Yes & $31(39)$ & $36(45)$ & $47(60)$ & $56(73)$ & $80(99)$ \\
R/No & $48(61)$ & $44(55)$ & $31(40)$ & $21(27)$ & $1(1)$ \\
\hline
\end{tabular}

aNot all health professionals answered every part of this question. GP, general practitioner: PN, practice nurse; R, Receptionist.

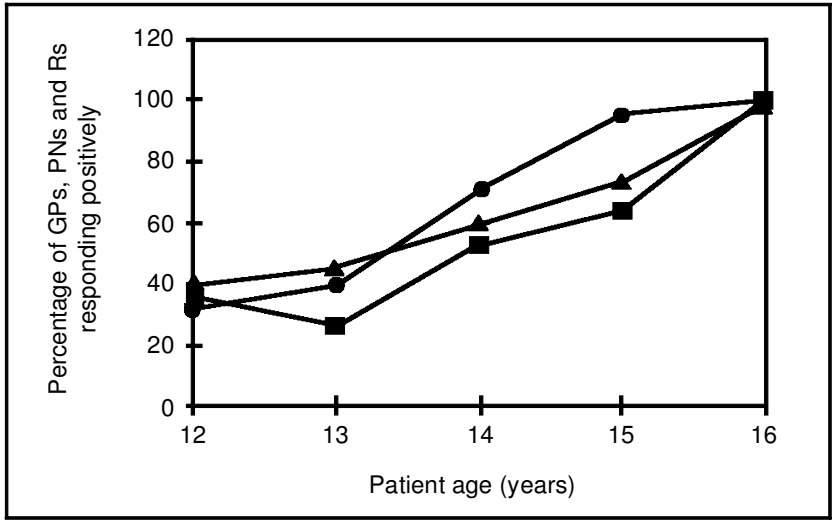

Figure 1 Percentage of general practitioners $(G P s, 0)$, practice nurses $(P N s, \mathbf{\square})$ and receptionists $(R s, \boldsymbol{\Delta})$ agreeing to offer unaccompanied appointments according to the age of the patient

unaccompanied under-16-year-old patients. GPs and PNs were asked what their expectations were with regard to which ages it was appropriate for reception to offer unaccompanied appointments. Receptionists were asked at what age would they normally offer an appointment without requesting a parent or guardian. The age range of 12-16 years was used. Table 1 details the responses of each group and shows both the number and percentage of GPs, $\mathrm{PNs}$ and receptionists that agreed/disagreed with the appropriateness of offering unaccompanied appointments.

These results have a degree of consistency for all the 17 practices, with the majority of receptionists, GPs and PNs willing to implement a policy that offered appointments to unaccompanied patients from 14 years of age upwards and a substantial number were willing to do this down to the age of 12 years (which was as low as this questionnaire surveyed) (Figure 1).

Fraser guidelines ${ }^{14}$

GPs and PNs were asked if they felt at ease with establishing Fraser competence. A total of 43/51 (84\%) GPs and 23/27 (85\%) PNs felt at ease with this question and hence, overall, 66/78 (85\%) health professionals felt able to implement the Fraser Guidelines in their daily practice. A minority of health professionals were unsure of the ruling (four GPs and three PNs).

\section{Discussion}

It is apparent from the results reported here that there is the potential for general practice in this area of England to provide a confidential service to adolescent patients without the prerequisite that under-16-year-olds should always be accompanied by a parent or guardian. With an overall response rate of $79 \%$ these results can be considered to minimise bias. ${ }^{15}$

The great majority of doctors and nurses (94\% of GPs and $85 \%$ of PNs) were willing to consult with unaccompanied under-16-year-old patients. This is in keeping with the legal standing of young people below the age of 16 years, which is reflected in the Children's Act of 1989 and the Fraser Guidelines. The study also reveals that under-16-year-olds will be treated appropriately as the results reflect a good understanding of Fraser Guidelines with $85 \%$ of GPs and PNs at ease with this concept. This ensures that the patient is able to follow the consultation and make informed decisions. It is important to communicate this information to young people to help them to be aware of their rights.

There were relatively few receptionists $(41 \%)$ who felt they had been given a clear policy to follow and even fewer GPs (38\%) and PNs (46\%). It is desirable that receptionists 
have clear guidelines when questioning all patients making appointments and that they follow a practice confidentiality agreement. ${ }^{16}$ The decision whether or not to consult with under-16-year-old patients should not be left with reception. Where a personal belief might prejudice patient care, it is the duty of the GP or PN to ensure that the patient has access to help from another source. This is in keeping with the General Medical Council guidance for good medical practice. ${ }^{17}$ Hence, receptionists need to know which members of the practice team are not happy to offer consultation to under-16-year-olds in order to make appropriate arrangements to deal with such requests.

There were similarities between receptionists and health professionals when examining actual age groups. Previous research has shown that young people begin to decide to attend on their own for health care at age 14-15 years and up to $50 \%$ of boys and girls have reported seeing their GP on their own at the age of 15 years. ${ }^{18,19}$ Table 1 and Figure 1 both illustrate an increase in the number of respondents allowing unaccompanied access from between the ages of 13 and 14 years. Although the overall willingness to consult with young, unaccompanied under16-year-olds was high, it would seem from these results that actual age makes a difference, with more uncertainty for patients aged under 14 years.

This study definitively is limited to a specific region and 17 practices hence it is not possible to extrapolate results beyond this region, e.g. inner city practices are not represented and regional attitudes may differ. However, evidence suggests that these differences may be minor and hence these results may have a general, national applicability. 20

This small-scale, local survey highlights several issues which merit further exploration. For instance, what are the prevailing views of health professionals as to the ease of making a decision about Fraser competence? What influence does actual age or gender have on decisions concerning unaccompanied consultations? Are there wide differences in what receptionists practice and what their doctors think they practice? Is access policy so poorly defined that the perceived barriers referred to are real?

Most adolescent studies centre around what young people want and these suggest that many want personcentred initiatives. ${ }^{15}$ Professionals, in contrast, tend to emphasise population approaches such as drop-in clinics and education. ${ }^{15}$ General practice is used regularly by young people and does provide a person-centred approach that deals with all health issues and not just those centred around the needs of contraception. It is therefore ideally suited to providing a service for young people. Under-16year-old adolescent patients should be able to ask for advice and be able to choose whether to be seen alone or accompanied by a friend rather than a parent, and should be encouraged to understand that this is allowed.

\section{Conclusions}

This survey shows that young people should be able to access help confidentially and confirms that practices are aware of the rights of young people. GPs and PNs are willing to consult without a parent or guardian being present.

The majority of the health professionals in this survey were not aware of a policy on access for unaccompanied under-16-year-olds.

\section{Acknowledgements}

The author would like to thank Drs F Dobbs, C Seamark and J Tilbury for their advice during the development of this project. Jo Keevil of Helston Medical Centre is thanked for administrative support. All the responders and the practice managers who distributed and collected the questionnaires are also thanked.
Statements on funding and competing interests

Funding. This project was partially funded by a Health Action Zone (HAZ) fellowship.

Competing interests. None identified.

References

1 Burrack R. Young teenagers' attitudes towards general practitioners and their provision of sexual health care. Br J Gen Pract 2000; 50: 550-554.

2 Macfarlane A, McPherson A. Primary health care and adolescence (Editorial). BMJ 1995; 311(7009): 825-826.

3 Davies LA, Casey S. Can you keep a secret? Nurs Times 1999; 95: 63-64.

4 Jacobson L, Wilkinson C, Pill RM, et al. Communication between teenagers and British general practitioners: a preliminary study of the teenage perspective. Ambul Child Health 1996; 1: 291-301.

5 Cheng TL, Savageau JA, Sattler AL, et al. Confidentiality in health care. A survey of knowledge, perceptions and attitudes among high school students. JAMA 1993; 269: 1404-1407.

6 Acton J, Dann C. Youth consultation 2000. Draft integrated rural strategy for Helston and the Lizard Peninsula. Results of consultation with young people for the Helston and Lizard Youth Forum, October $1999 ; 4-5$

7 Amery M, Hughes L. Listening to young people; a research project into unplanned teenage pregnancy in North Cornwall. 1998; 5. Document produced by the Cornwall Youth Service and the Cornwall and Isles of Scilly Health Authority Health Promotion Service.

8 Jacobson L, Richardson G, Parry-Langdon N, et al. How do teenagers and primary healthcare providers view each other? An overview of key themes. Br J Gen Pract 2001; 51: 811-816.

9 White R, Carr P, Lowe N. A guide to the Children's Act 1989. London: Butterworths, 1990.

10 Higgs R. Child autonomy. Practitioner 1992; 236: 1031-1035.

11 The Social Exclusion Unit. Teenage pregnancy. The Stationery Office, June 1999.

12 Walker ZA, Townsend J. The role of general practice in promoting teenage health: a review of the literature. Fam Pract 1999; 16: $164-172$.

13 Churchill D, Allen J, Pringle M, et al. The consultation patterns and provision of contraception in general practice before teenage pregnancy: case control study. BMJ 2000; 321: 486-489.

14 BMA, GMSC, HEA, Brook Advisory Centres, FPA, RCGP Confidentiality and people under 16. London: British Medical Association, 1993.

15 Lydeard S. The questionnaire as a research tool. Fam Pract 1991; 8: 84-91.

16 Confidentiality and young people: a toolkit for general practice, primary care and trusts. London: Royal College of General Practitioners and Brook, 2000.

17 Good medical practice. Decisions about access to medical care (3rd edn). London: General Medical Council (GMC) Guidance, May 2001.

18 Balding J. Young people into the nineties. Book 1. Doctor and dentist. Exeter: University of Exeter, Schools Health Education Unit, 1991.

19 Jacobson L, Owen P. Study of teenage care in one general practice (Letter). Br J Gen Pract 1993; 43: 349.

20 Hammersley V, Hippisley-Cox J, Wilson A, et al. A comparison of research general practices and their patients with other practices - a cross-sectional survey in Trent. Br J Gen Pract 2002; 52: 463-468.

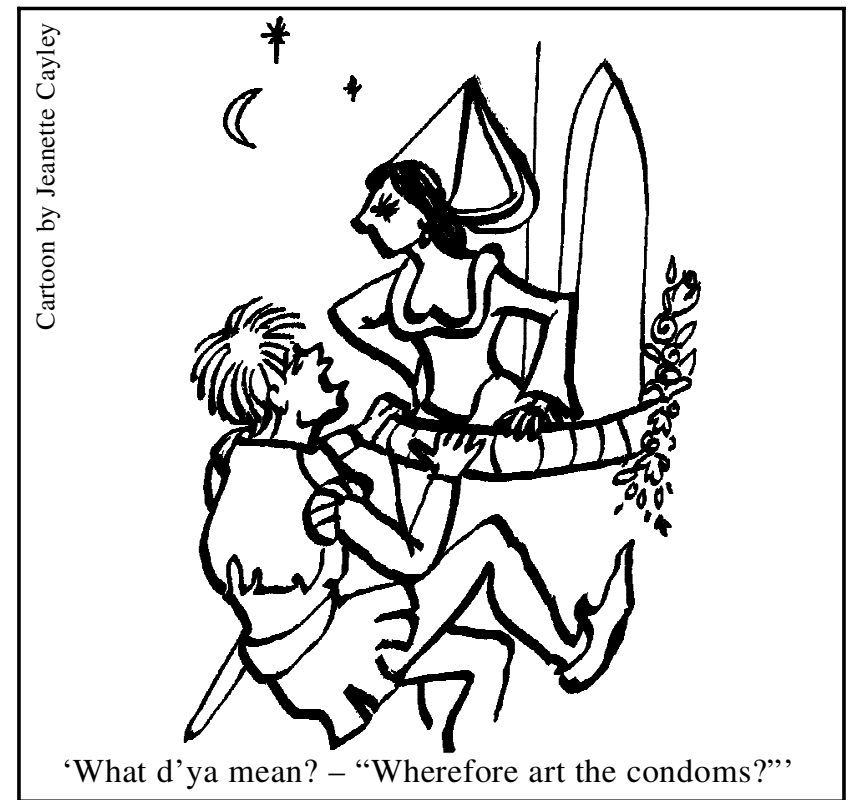

